\title{
Determinants and importance of atrial pressure morphology in atrial septal defect
}

\author{
DINESHKANT N PARIKH, „ JEFFREY FISHER, JEFFREY W MOSES, \\ HARVEY L GOLDBERG, AARON R LEVIN, MARY ALLEN ENGLE, JEFFREY S BORER
}

From the Divisions of Adult and Pediatric Cardiology, New York Hospital-Cornell Medical Center, New York, USA

SUMMARY A prominent " $v$ " wave relative to the "a" wave in the jugular vein and right atrial pressure tracing is considered to be a common haemodynamic sign of atrial septal defect. Since the prevalence, age relation, and haemodynamic determinants of the " $v$ " $\geqslant$ " $a$ " wave configuration have not been studied the pressure recordings from 15 adults and 80 children with an isolated secundum atrial septal defect in sinus rhythm and from 40 adults and 55 children in sinus rhythm without structural cardiac abnormalities or with coronary and valvular heart disease were studied to assess the sensitivity and specificity of the " $v$ " $\geqslant$ " $a$ " wave configuration in atrial septal defect. Only $20 \%$ of adults with an atrial septal defect had prominent right atrial " $v$ " waves compared with $63 \%$ of children, although the specificity was quite high for each group. In adults "left atrialisation" of the right atrium (" $v$ " $\geqslant " a "$ wave) occurred in younger patients with higher right atrial and right ventricular end diastolic pressures. In contrast, in children no age related or haemodynamic determinants for the " $v$ " $\geqslant$ " $a$ " pattern were found. In addition, most adults but few children with an atrial septal defect had "right atrialisation" of the left atrial wave configuration ("a"> "v"). This was found in older adults with lower right atrial and right ventricular end diastolic pressures and in older children with larger left to right shunts.

Thus in contrast to children adults with an atrial septal defect rarely show a prominent " $v$ " wave in the right atrium. The presence of a prominent right atrial " $v$ " wave in adults with an atrial septal defect is associated with relatively higher left atrial and right heart pressures than is the absence of this sign and may be related to relatively higher systolic transatrial flow in these patients. The relative paucity of prominent right atrial " $v$ " waves in older adults suggests that the systolic phase flow may diminish with age, possibly from progressive alteration in compliance of the chronically dilated right ventricle.

Prominence of the " $v$ " wave relative to the " $a$ " wave in the jugular venous pulse-a reflection of a similar finding in the right atrium-has been considered to be a common diagnostic physical sign in patients with an atrial septal defect. ${ }^{1-3}$ Development of "left atrialisation" ("v" wave $\geqslant$ "a" wave or " $v$ " $\geqslant$ "a") of the right

Requests for reprints to Dr Jeffrey S Borer, New York HospitalCornell Medical Center, 525 East 68th Street, New York, NY 10021, USA.

^Present address: Division of Cardiology, Veteran Administration Medical Center, Asheville, North Carolina 28805, USA.

Accepted for publication 1 November 1983 atrial pressure tracing has been attributed to the size of the interatrial defect and the magnitude of the shunt. 1 The presence of the otherwise normal "a" " " $v$ " wave pattern in the right atrial and jugular venous tracing in patients with an atrial septal defect has been associated with prolongation of the PR inter$\mathrm{val}^{4}$ and the Eisenmenger syndrome. ${ }^{56}$ The observations on which these conclusions were based were, however, made in small numbers of selected patients; the prevalence, age relation, and haemodynamic determinants of these wave patterns in a larger and more representative group of patients with atrial septal defect are unknown.

Preliminary observations in our laboratory suggested that left atrialisation was uncommon in adults 
with atrial septal defects. To determine the incidence of this finding and its age dependence and to clarify its potential haemodynamic implications, we retrospectively analysed pressure tracings from 95 adults and children with an atrial septal defect and 95 selected patients without.

\section{Patients and methods}

\section{ADULTS}

Twenty adults with a secundum atrial septal defect underwent cardiac catheterisation at this hospital between February 1978 and February 1982. Fifteen of these patients (six men, nine women; age range 21-56 (mean 43) years) without coronary or other detectable additional heart disease were in normal sinus rhythm at the time of catheterisation, and data from these were included in this study. Pressure tracings recorded in adults with atrial septal defect were compared with those of $\mathbf{4 0}$ adults without. Of these, 20 (aged 26-69 years) were in sinus rhythm during catheterisation, which was undertaken because of coronary artery disease. All had a $\geqslant 50 \%$ reduction in luminal diameter of at least one coronary artery and normal left ventricular systolic function. The other 20 adults (aged 24-76 years) were also in sinus rhythm at the time of catheterisation between January and June 1982 for valvular heart disease. No factors other than the technical adequacy of tracings were used in selecting comparative tracings for study.

\section{CHILDREN}

One hundred children with isolated secundum atrial septal defects underwent cardiac catheterisation at this hospital between October 1966 and February 1982. Of these, 80 ( 27 boys, 53 girls; age range 5 months to 16 (mean 6) years) were in sinus rhythm and had technically adequate tracings and served as our paediatric study group. For comparison, tracings were also analysed (a) from 40 children ("normal" group) (aged 2-18 years), who were catheterised for a suspected atrial septal defect but who had no abnormality at catheterisation, and (b) from 15 children (aged 2-12 years) with mild pulmonary stenosis (mean ( \pm SD) transpulmonary valve gradient $31 \pm 16 \mathrm{~mm}$ $\mathrm{Hg}$ ) who were also in sinus rhythm and without atrial septal defect.

\section{RECORDING OF PRESSURES}

Pressures were recorded with single lumen fluid filled catheters attached to Statham P23 DB pressure transducers. The zero reference point for pressure was 5 $\mathrm{cm}$ deep to the anterior thorax in adults and was at the mid-thoracic level in children. Phasic atrial pressures were recorded at $50 \mathrm{~mm} / \mathrm{s}$ and mean pressures at 10 $\mathrm{mm} / \mathrm{s}$. In all patients studied mean pressures were recorded during pullback from the left atrium to the right atrium. Right and left atrial phasic pressures were recorded immediately before and immediately after interatrial pullback respectively. Pressure measurements were recorded for at least three respiratory cycles, and the result from at least three cycles was averaged. The pressure wave following the electrocardiographic $P$ wave was identified as the "a" wave, and that coinciding with or following the $T$ wave was identified as the "v" wave. Haemodynamic tracings were reviewed by four of us and a consensus on the mean and phasic pressures was reached.

\section{STATISTICAL ANALYSIS}

Data were analysed using paired and unpaired two tail $t$ tests and the $\chi^{2}$ test. Data are expressed as means \pm standard deviation.

\section{Results}

\section{HAEMODYNAMIC FINDINGS}

Haemodynamic findings in both adults and children with atrial septal defects are shown in Table 1. All patients had left to right shunts and two adults had bidirectional shunts. No patient had increased pulmonary vascular resistance or a predominant right to left shunt.

Haemodynamic comparisons between adults and children with atrial septal defects (Table 1 ) showed no differences in mean right atrial pressure, right atrial "a" or " $v$ " wave amplitude, right ventricular systolic pressure, mean left atrial pressure, or left atrial "a" or " $v$ " wave amplitude, although right ventricular end diastolic, pulmonary artery systolic, diastolic, and mean, and left ventricular systolic and end diastolic pressures were higher in the adults.

\section{Adults}

Patients with atrial septal defects were younger than those with coronary artery disease or valvular heart disease $(43 \pm 12$ vs $56 \pm 12$ and $59 \pm 16$ years respectively, $\mathrm{p}<0.01)$. Right atrial mean pressures, "a" and "v" wave pressures, and right ventricular and pulmonary artery systolic pressures were higher in patients with atrial septal defect than in those with coronary artery disease but were of the same magnitude as in those with valvular heart disease (Table 1). Left ventricular systolic and diastolic and pulmonary artery diastolic pressures were higher in adults with valvular heart disease than in those with an atrial septal defect, as was pulmonary vascular resistance.

\section{Children}

Children with an atrial septal defect were younger than the "normal" group ( $6 \pm 3$ vs $10 \pm 5$ years, $p<0.001$ ) but were the same age as those with pulmo- 
Table 1 Haemodymamic data in adults with atrial septal defects (ASD), coronary artery disease (CAD), and valvular heart disease (VHD) and children with atrial septal defects, pulmonary stenosis (PS), and with murmurs but no ASD ("normal").Values are means $\pm S D$

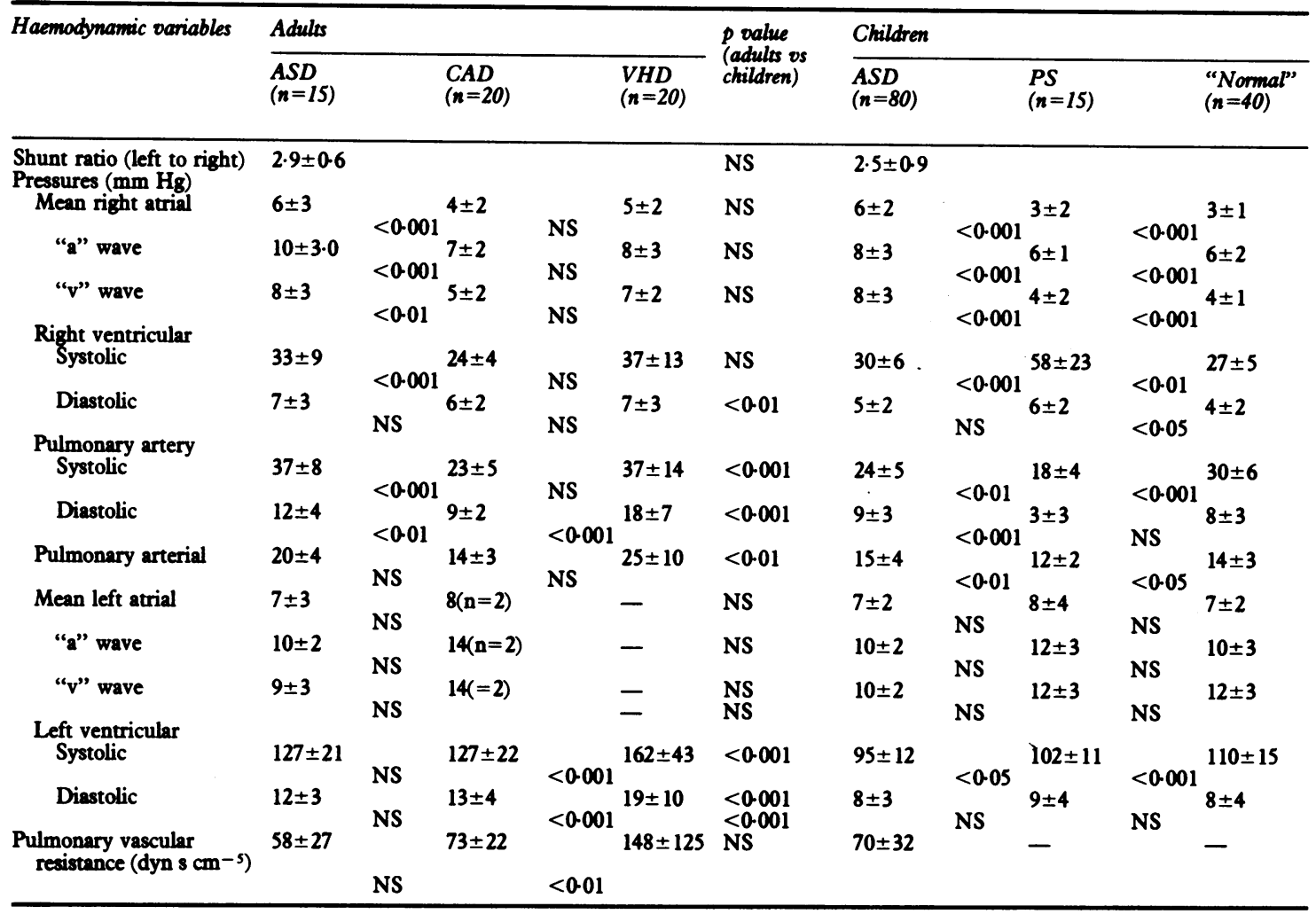

nary stenosis ( $8 \pm 4$ years, NS). The haemodynamic data on children with atrial septal defects and those with murmurs but no demonstrable abnormalities (normal group) or children with mild pulmonary stenosis are also compared in Table 1. Mean right atrial pressure and right atrial "a" and " $v$ " wave amplitudes were higher in children with an atrial septal defect than in either the normal group or those with

Table 2 Deteminants of right atrial wave monphology in adults and children with atrial septal defect. Values are means $\pm S D$

\begin{tabular}{|c|c|c|c|c|c|c|}
\hline & \multicolumn{3}{|l|}{ Adults } & \multicolumn{3}{|l|}{ Children } \\
\hline & $\begin{array}{l}\text { "a">"v" } \\
(n=12)\end{array}$ & & $\begin{array}{l}\text { "v" }(n=3) \\
(n)\end{array}$ & $\begin{array}{l}\text { "a"> "v" } \\
(n=30)\end{array}$ & & $\begin{array}{l}\text { " } \sigma " \geqslant " a " \\
(n=50)\end{array}$ \\
\hline Age (yr) & $46 \pm 9$ & $<0.01$ & $28 \pm 7$ & $6 \pm 4$ & NS & $7 \pm 3$ \\
\hline Shunt ratio (left to right) & $2.9 \pm 0.6$ & NS & $2.7 \pm 0.7$ & $2.5 \pm 0.9$ & NS & $2.5 \pm 1.0$ \\
\hline PR interval (8) & $0.19 \pm 0.03$ & & $0.18 \pm 0.03$ & $0.15 \pm 0.02$ & NS & $0.15 \pm 0.02$ \\
\hline $\begin{array}{l}\text { Pressures }(\mathbf{m m} \mathbf{~ H}) \\
\text { Right atrial }\end{array}$ & $6 \pm 3$ & $<0.05$ & $9 \pm 2$ & $6 \pm 2$ & NS & $6 \pm 2$ \\
\hline Right ventricular diastolic & $6 \pm 2$ & $<0.01$ & $11 \pm 2$ & $6 \pm 3$ & NS & $5 \pm 2$ \\
\hline Pulmonary arterial & $19 \pm 4$ & NS & $22 \pm 3$ & $15 \pm 4$ & NS & $15 \pm 4$ \\
\hline Left atrial & $6 \pm 3$ & NS & $9 \pm 2$ & $7 \pm 2$ & NS & $7 \pm 2$ \\
\hline Left ventricular diastolic & $12 \pm 4$ & NS & $11 \pm 3$ & $9 \pm 3$ & NS & $7 \pm 3$ \\
\hline
\end{tabular}


Table 3 Determinants of left atrial wave morphology in adults and children with atrial septal defect. Values are means $\pm S D$

\begin{tabular}{|c|c|c|c|c|c|c|}
\hline & \multicolumn{3}{|l|}{ Adults } & \multicolumn{3}{|l|}{ Children } \\
\hline & $\begin{array}{l}\text { "a">"v" } \\
(n=10)\end{array}$ & & $\begin{array}{l}\text { " } v " \geqslant " a " \\
(n=5)\end{array}$ & $\begin{array}{l}\text { "a"> } a " v " \\
(n=16)\end{array}$ & & $\begin{array}{l}\text { "v" } \geqslant " a " \\
(n=64)\end{array}$ \\
\hline Age (yr) & $48 \pm 8$ & & $30 \pm 6$ & $8 \pm 4$ & & $6 \pm 3$ \\
\hline Shunt ratio (left to right) & $3.0 \pm 0.5$ & & $2.6 \pm 0.7$ & $3 \cdot 4 \pm 2 \cdot 5$ & NS & $2.5 \pm 0.9$ \\
\hline PR interval (s) & $0.19 \pm 0.03$ & NS & $0.19 \pm 0.03$ & $0.15 \pm 0.02$ & NS & $0.15 \pm 0.03$ \\
\hline $\begin{array}{l}\text { Pressures }(\mathrm{mm} \mathrm{Hg} \text { ) } \\
\text { Right atrial }\end{array}$ & $6 \pm 3$ & $<0.05$ & $8 \pm 2$ & $6 \pm 2$ & NS & $6 \pm 2$ \\
\hline Right ventricular diastolic & $6 \pm 2$ & $<0.02$ & $8 \pm 3$ & $6 \pm 3$ & NS & $7 \pm 3$ \\
\hline Pulmonary arterial & $19 \pm 4$ & NS & $21 \pm 4$ & $15 \pm 3$ & NS & $16 \pm 7$ \\
\hline Left atrial & $6 \pm 3$ & $<0.05$ & $8 \pm 2$ & $6 \pm 2$ & NS & - \\
\hline Left ventricular diastolic & $12 \pm 3$ & NS & $11 \pm 3$ & $8 \pm 2$ & NS & $8 \pm 3$ \\
\hline
\end{tabular}

pulmonary stenosis.

\section{RIGHT ATRIAL WAVE MORPHOLOGY}

Three of the 15 adults with atrial septal defect had an abnormal right atrial wave contour ("v" $\geqslant$ "a"). The sensitivity of the " $v$ " $\geqslant$ " $a$ " wave morphology sign in identifying adults with atrial septal defect was, therefore, $20 \%$. None of the adults with coronary artery disease had a " $v " \geqslant " a$ " in the right atrial pressure tracing, but two of 20 with valvular disease had this finding. The specificity of this haemodynamic sign was, therefore, $100 \%$ in patients with coronary artery disease and $90 \%$ in those with valvular heart disease.

Fifty of the 80 children with atrial septal defect had the " $v$ " $\geqslant$ "a" wave pattern in the right atrial pressure tracing (sensitivity 63\%). The "v" $\geqslant$ "a" wave pattern was seen in nine of $\mathbf{4 0}$ children in the normal group and in none of the 15 with mild pulmonary stenosis. The specificity of this sign for atrial septal defect in the normal group with heart murmurs but no demonstrable structural abnormality was, therefore, $78 \%$; specificity was $100 \%$ in children with mild pulmonary stenosis. None of the nine children in the normal group with the " $v$ " $\geqslant$ " $a$ " pressure configuration in the right atrial tracing had a right ventricular end diastolic pressure greater than $6 \mathrm{~mm} \mathrm{Hg}$.

\section{DETERMINANTS OF RIGHT ATRIAL WAVE MORPHOLOGY}

The three adults with an atrial septal defect and left atrialisation of the right atrial wave morphology were younger, had higher mean right atrial pressure, and higher right ventricular end diastolic pressure than those adults with the normal " $a$ " $>$ " $v$ " wave pattern (Table 2). No differences in shunt ratio, pulmonary artery pressure, or left ventricular end diastolic pressure were apparent between the two subgroups, nor was the distribution of a prolonged PR interval different in the two subgroups (four of 12 prolonged in "a" $>$ " $v$ " group, one of three prolonged in " $v$ " $\geqslant$ " $a$ " group). Two of the 15 adults with an atrial septal defect had a history of systemic hypertension; the " $a$ " wave was larger than the " $v$ " wave in both the right and left atrium in these patients.

As seen in Table 2, there were no age or haemodynamic differences in children with an atrial septal defect to account for the presence or absence of left atrialisation of the right atrial wave morphology (Table 2).

\section{DETERMINANTS OF LEFT ATRIAL PRESSURE WAVE MORPHOLOGY}

As seen in Table 3, 10 of $15(67 \%)$ adults with an atrial septal defect had right atrialisation of the left atrial pressure wave morphology ("a"> " $v$ "). These patients were older and had lower mean right atrial pressure, lower right ventricular end diastolic pressure, and lower mean left atrial pressure than those with the normal ("v" $\geqslant$ "a") pattern in the left atrium. No statistically significant difference in shunt ratio was found between those patients with and those without right atrialisation, although shunts tended to be larger in patients with right atrialisation. No differences in the PR interval, pulmonary artery pressure, or left ventricular end diastolic pressure were noted between the subgroups, and the proportions of patients with abnormalities of each of these variables were also statistically insignificant.

In contrast with adult patients, only 16 of 80 children $(20 \%, p<0.001$ vs adults) had right atrialisation of the left atrial pressure wave morphology. Children with right atrialisation were older and had larger left to right shunts than those with the normal " $v$ " $\geqslant$ " $a$ " wave pattern in the left atrium, although shunt sizes 
clearly overlapped among those with and those without right atrialisation: 11 of $16(69 \%)$ with right atrial morphology in the left atrium had shunt ratios of 2.0:1, and 39 of $64(61 \%)$ without right atrialisation had shunts of this magnitude (NS).

\section{DISCORDANCE OF ATRIAL PRESSURES \\ Mean pressures}

All 15 adults with atrial septal defects had equalisation of the right and left atrial pressures, while only 27 of $80(34 \%)$ children ( $p<0.001$ vs adults) had such equalisation. The remaining 53 children had mean left atrial pressures greater than mean right atrial pressures. The haemodynamic concomitants of mean atrial pressure discordance in children with atrial septal defect are shown in Table 4. Those patients with equalisation of mean atrial pressures had larger left to right shunts and higher mean right atrial, phasic right atrial, right ventricular systolic, pulmonary artery systolic and diastolic, and lower left atrial " $v$ " wave pressures than did those with unequal mean atrial pressures.

\section{Phasic pressures}

Adults-Of 12 adults with an atrial septal defect and "a" $>$ " $v$ " in the right atrial pressure tracing 10 also had " $a$ " $>$ " $v$ " in the left atrium, including the two patients with a bidirectional shunt. The two adults with the " $v$ " $\geqslant$ "a" wave pattern in the left atrium but " $a$ " $>$ " $v$ " in the right atrium were younger than the other 10 adults ( 29 and 36 years vs $49 \pm 8$ years, range 21-77 years) and tended to have smaller left to right shunts (1.9:1 and $2.8: 1$ vs $3.0 \pm 0.5: 1$, range 1.8 3.8:1).

Children-Of the 80 children with atrial septal defects, 30 had the " $a$ " $>$ " $v$ " wave pattern in the right atrium. Of these 30 , nine had right atrialisation (" $a$ " > " $v$ ") of the left atrial pressure tracing, and the remaining 21 had the expected " $v$ " $\geqslant$ " $a$ " wave pattern in the left atrium. Those with concordance of the " $a$ " $>$ " $v$ " atrial pressures were older $(8+5$ vs $5 \pm 3$ years, $p<0.05$ ) and had higher right ventricular systolic pressures $(34 \pm 9$ vs $28 \pm 7 \mathrm{~mm} \mathrm{Hg}, \mathrm{p}<0.05)$ than those with the " $v$ " $\geqslant$ " $a$ " in the left atrium and "a" $>$ " $v$ " in the right atrium. Fifty had " $v " \geqslant$ " $a$ " in the right atrium. Of these, 43 had left atrial concordance with " $v$ " $\geqslant$ "a". Seven of the 50 , however, had phasic atrial discordance with right atrialisation of the left atrium despite left atrialisation of the right atrium. No variables differed significantly between those children with and those without concordance of phasic atrial pressures when left atrialisation of the right atrium was present.
Table 4 Determinants of mean atrial pressure discordance in children with atrial septal defect. Values are means $\pm S D$

\begin{tabular}{|c|c|c|c|}
\hline & $\begin{array}{l}R A=L A \\
(n=27)\end{array}$ & & $\begin{array}{l}R A<L A \\
(n=53)\end{array}$ \\
\hline Age (yr) & $6 \pm 3$ & \multirow{3}{*}{$\begin{array}{l}\text { NS } \\
\text { NS } \\
\text { NS }\end{array}$} & $6 \pm 3$ \\
\hline Shunt ratio (left to right) & $3 \pm 1 \cdot 0$ & & $2 \cdot 3 \pm 0.8$ \\
\hline PR interval (s) & $0.15 \pm 0.03$ & & $0.15 \pm 0.02$ \\
\hline $\begin{array}{l}\text { Pressures (mm Hg) } \\
\text { Mean right atrial }\end{array}$ & $7 \pm 2$ & $<0.01$ & $5 \pm 2$ \\
\hline "a" wave & $9 \pm 2$ & $<0.01$ & $8 \pm 3$ \\
\hline "v" wave & $9 \pm 2$ & $<0.01$ & $7 \pm 3$ \\
\hline $\begin{array}{l}\text { Right ventricular } \\
\text { Systolic }\end{array}$ & $34 \pm 7$ & $<0.001$ & \\
\hline Diastolic & $6 \pm 3$ & & $5 \pm 2$ \\
\hline $\begin{array}{l}\text { Pulmonary arterial } \\
\text { Systolic }\end{array}$ & $26 \pm 5$ & $<0.05$ & $23 \pm 5$ \\
\hline Diastolic & $9 \pm 3$ & $<0.05$ & $8 \pm 3$ \\
\hline Pulmonary arterial & $16 \pm 4$ & NS & $15 \pm 3$ \\
\hline & & NS & $7 \pm 2$ \\
\hline “a" wave & $10 \pm 2$ & NS & $10 \pm 3$ \\
\hline "v" wave & $10 \pm 3$ & $<0.05$ & $11 \pm 3$ \\
\hline $\begin{array}{l}\text { Left ventricular } \\
\text { Systolic }\end{array}$ & $93 \pm 11$ & NS & $96 \pm 13$ \\
\hline Diastolic & $8 \pm 2$ & NS & $8 \pm 3$ \\
\hline $\begin{array}{l}\text { Pulmonary vascular } \\
\text { resistance (dyn s cm-5) }\end{array}$ & $65 \pm 31$ & NS & $72 \pm 32$ \\
\hline
\end{tabular}

RA, right atrial pressure; LA, left atrial pressure.

\section{Discussion}

The presence of left atrialisation (" $v$ " wave $\geqslant$ " $a$ " wave) in the right atrium and jugular vein is generally considered to be common in patients with an uncomplicated atrial septal defect, ${ }^{1-3}$ but its prevalence has not been precisely defined nor have its age dependence and haemodynamic determinants been well clarified. Our data indicate that this physical sign is age dependent and is absent in most adults with atrial septal defect. Moreover, although quite common in children, it is not ubiquitous in this group, having been found in only $63 \%$ of children in this study, and it is relatively less specific for atrial septal defects in children. We conclude from these data that contrary to clinical teaching, ${ }^{23}$ while identification of the " $v$ " $\geqslant$ " $a$ " wave form is helpful in the clinical diagnosis of uncomplicated atrial septal defect, its absenceparticularly in adults-does not strongly mitigate against the diagnosis, and its presence in children is not by itself diagnostic.

Previous investigators have associated the presence 
of a "normal" "a" $>$ "v" wave pattern in the right atrium in patients with atrial septal defect either with first degree heart block ${ }^{4}$ or with the Eisenmenger syndrome. ${ }^{56}$ In the present study, no patient had raised pulmonary vascular resistance. Indeed, we found that adults with "a"> " $v$ " wave morphology had lower right heart pressures than those with the "v" $\geqslant$ " $a$ " wave pattern, which is the opposite to what might be expected if an Eisenmenger type reaction was a major determinant. Moreover, we found no significant haemodynamic predictors of right atrial wave morphology in the children.

Prolongation of the PR interval was seen in only one third of the adults with the "normal" "a" $>$ "v" right atrial pressure tracing and in only one of the children. First degree heart block, therefore, is clearly not the only explanation for the " $a$ " $>$ " $v$ " right atrial wave morphology in patients with atrial septal defect. In addition, one of the three adults with the " $v$ " $\geqslant " a$ " pattern in the right atrium had first degree heart block.

The majority of adults (10/15) but only a small proportion of children (16/80) had right atrialisation of the left atrium. In adults, right atrialisation occurred in older patients with lower right and left atrial pressures; although shunt size was not a statistically significant determinant, left to right shunts tended to be larger in adults with right atrialisation of the left atrium. In the paediatric group, the older children with relatively larger left to right shunts had reversal of the normal left atrial wave pattern, although a pronounced overlap in shunt magnitude was noted among those with and those without right atrialisation. We conclude that while shunt size is of some importance in determining the likelihood of right atrialisation of the left atrial pressures in atrial septal defect the relation is modest and is of importance only in children.

Thus in patients with isolated atrial septal defect atrial wave morphology is most clearly related to age and hence to the chronicity of the shunt. Shunt size and right ventricular and right atrial pressures are apparently somewhat less important determinants of certain wave form characteristics. Previous investigations into the haemodynamic mechanisms responsible for observed pressure-flow relations in atrial septal defect (of which wave forms are one manifestation) have emphasised the potential importance of differences in wall thickness of the two atria, in the size of venous reservoirs (pulmonary and systemic) and in the muscular development of the two ventricles, ${ }^{7-9}$ leading to the inference that modest decreases in atrial and ventricular compliance may play an important part in determining atrial wave configuration. Measures of compliance were not obtained in this study. Nevertheless, the two adults with atrial septal defect - and systemic hypertension-often associated with diminished left ventricular compliance-showed the " $a$ " > " $v$ " pattern in both atria, although left ventricular end diastolic pressure was not a determinant of atrial wave morphology in our group.

Perhaps the most important insight into the mechanisms underlying the development of abnormal wave forms associated with atrial septal defect comes from the work of Paul Wood, who characterised the interatrial flow patterns resulting from atrial septal defect. Wood found that interatrial flow in children occurs predominantly during systole with the " $v$ " wave. ${ }^{10}$ In contrast, in adults who have had sufficiently severe and long standing defects so that atrial fibrillation has supervened, tricuspid regurgitation is invariably present, and interatrial flow is diastolic with associated signs of right heart volume overload. ${ }^{11}$ The apparent relation between age and specific temporal patterns of flow in Wood's series may at least partly explain our observation of the importance of age and disease chronicity in determining wave form and is consistent with our findings that most children but no adults had a mean transatrial pressure gradient (a primary determinant of transatrial flow). Moreover, the flow patterns seen by Wood and the transatrial pressure data noted in the present study are both consistent with the concept that age related changes in atrial and ventricular compliance may ultimately account for the atrial wave form abnormalities.

Apart from determining the value of assessing jugular venous wave morphology in the diagnosis of atrial septal defect, the clinical implications of our findings are unclear. Since in adults a prominent right atrial " $v$ " wave is associated with a mild to moderate increase in right heart pressures it might be inferred that early closure of the septal defect might be more imperative. However, our data do not include information on the clinical course, and we cannot therefore comment on such a potentially important possibility. Further study is necessary to ascertain the clinical implications of our observations and, as a corollary, to determine more precisely the physiological basis of altered wave morphology.

We thank Barry Cohen, Salud Dejoya, Margaret Mermelstein, Richard Quiroz, Margaret Ratigan, Sheila Reams, and Nancy Skelly for their invaluable technical assistance in obtaining the catheterisation data used in this study.

JSB was supported in part by the American Heart Association during this study.

\section{References}

1 Rudolph AM. Congenital diseases of the heart. Chicago: Year Book, 1974; 131-6, 258-9. 
2 Perloff JK. The clinical recognition of congenital heart disease. 2nd ed. Philadelphia: WB Saunders, 1978: 293.

3 Tavel ME. Clinical phonocardiography and external pulse recording. 3rd ed. Chicago: Year Book, 1978: 237.

4 Somerville J. Atrial septal defect-simple secundum and sinus venous defects. Practical Cardiology 1979; 98-121.

5 Wood P. The Eisenmenger syndrome or pulmonary hypertension with reversed central shunt. $\mathrm{Br}$ Med $\mathcal{F}$ 1958; ii: 701-9, 755-62.

6 Brammell HL, Vogel JHK, Pryor R, Blount SG Jr. The Eisenmenger syndrome, a clinical and physiological reappraisal. Am f Cardiol 1971; 28: 679-92.

7 Levin AR, Spach MS, Boineau JP, Conent RV Jr, Capp MP, Jewett PH. Atrial pressure-flow dynamics in atrial septal defects (secundum type). Circulation 1968; 37: 476-88.
8 Cournand A, Motley HL, Himmelstein A, Dresdale D, Baldwin J. Recording of blood pressure from the left auricle and the pulmonary veins in human subjects with interauricular septal defect. Am $\mathcal{F}$ Physiol 1947; 150: 267-71.

9 Braunwald E, Fishman AP, Cournand A. Time relationship of dynamic events in the cardiac chambers, pulmonary artery and aorta in man. Circ Res 1956; 4: 100-7.

10 Wood P. Fate of the child with unrelieved congenital heart disease. Atrial septal defect. In: Morse DP, ed. Congenital heart disease. Philadelphia: FA Davis, 1962: $49-54$.

11 Wood $P$. The cause of a high jugular venous pressure in certain cases of atrial septal defect [Abstract]. Br Heart $\mathcal{F}$ 1958; 20: 589. 